\title{
Finite element method investigation of geometrical influences of adhesive and patch in the safety for $90^{\circ}$ elbow piping system
}

\author{
Ibrahim Gadi', Madjid Meriem-Benziane ${ }^{1 *}$, B. Bachir Bouiadjra ${ }^{2}$ \\ ${ }^{1}$ LRM, Mechanical Engineering Department, Faculty of Technology, Hassiba Benbouali \\ University of Chlef, P. O. Box 151, Esalem City, 02000, Chlef, Algeria. \\ Email: mbmadid2001@yahoo.fr \\ Phone: 00213277217 94; Fax: 0021327721794 \\ ${ }^{2}$ L5973MPM, Department of Mechanical Engineering, University of Sidi Bel Abbes, Algeria
}

\begin{abstract}
Piping system elbow study is the most important part in all fields of hydrocarbons transportation which presents the behaviour of circumferential crack at elbow extrados. The effect of geometry of adhesive and patch in the crack elbow is important in pipeline safety. This study shows the details for along the direction of the circumferential elbow crack by three dimensional (FEM) which is used to determine the stress intensity factor at $90^{\circ}$ elbow for two cases: firstly, without patch and secondly, repaired with composite patch. This method allows to predict the behaviour of cracked elbow through the analysis of crack propagation under the internal different pressures taking into consideration the operating conditions. The geometry and nature of composite patch proved that the increase of patch thickness leads to decrease the SIF from $7 \mathrm{MPa} \cdot \mathrm{m}^{1 / 2}$ to $6.15 \mathrm{MPa}^{1 / 2}$. It can be concluded that the repairing by composite materials leads to reduce the stress intensity factor with patch which not only can augment the lifetime of pipeline but also decreasing the costs and the pollution.
\end{abstract}

Keywords: Elbow, crack, bonded composite repair, stress intensity factor, finite element method.

\section{INTRODUCTION}

The pipeline system is still the most important way to transport an oil and gas to worldwide where the energy demand has been increasing for decade [1]. The transportation of hydrocarbons based to improve the fabrication defects of pipeline which may be among the reasons that lead to cracks. Most cracks have grown from small defects that were showed during operation of piping systems product or weld [1]. The piping system is regularly needed to manufacture the pipeline elbows by bending the length of pipelines to the necessary geometry forms [2]. Nowadays, engineers are seeking to find ways to improve the pipeline designs taking into account the stress distribution in different zones wall thicknesses. In addition, the mechanical characteristics of materials are important the pipe-line designer taking into account on the one hand, the industrialization costs and, on the other hand, the dimensions of geometric [2,3]. Pipelines elbows are usually used in hydrocarbon transports which are more flexible part in the piping system $[4,5]$. The dangerous part of piping system 
is the pipe elbow where it is important part of piping system which has been largely used in to link the pipes for hydrocarbons transport [4].

Some studies have illustrated the effect the stress produced by the internal pressure on the wall, especially in crack zone of pipelines [3-5]. The effect of crack in the elbow geometry is important in the piping system where it is the result of bad fabrication operations such as, quality of materials, exterior environment and boundary conditions (pressure, temperature and nature of fluids transported) which lead to damage in the energy transport $[6]$.

Given the importance of pipeline transport and especially the elbow is the biggest challenge for engineers in terms of elbow shape, load, and degree of bending and radius of bend taking into account limit of pressure. The elbow is the most dangerous part in pipeline and is critical component in piping systems because it is more complicated than straight pipeline which has been hugely used in transport of energy like gas and crude oil where it must be designed by effective methods with the new materials such as composite materials to avoid failure [7]. The finite element method three-dimensional was used to predict accurately the behaviour of elbow crack. Besides, to predict fracture or fatigue of elbow, the stress intensity factors accurately were investigated through a refined mesh around the elbow crack tip taking a consideration the dimensions and the bend angle [8-11]. Many studies proved that the angle of orientation of the patch, its geometry and its nature of material are among important secrets of design to decrease the fracture and fatigue. It can be noted that the SIF value increases as a result of increasing the crack angle and increasing the deeper of crack [8-12].

Numerical simulation by finite element method is very important to calculate the stress intensity factor which depends on crack energy where this approach is divides the cracks zone into two parts, first part around a crack and second part for the rest of structure [10-14]. The impact of the reinforced composite patches through decreasing of the stress at the small crack is challenge for each petroleum companies. It has been used the finite element method to calculate the stress intensity factors which helpful the prediction of the behaviour the small crack propagation phenomenon and its treatment [10-16]. The finite element method three-dimensional is used to compute the stress intensity factors which are resulted on the inclined cracks of the internal surface. It can be noted that the effect of the crack angle and the crack depth lead to decrease the stress intensity factors for the mode I and to increase the stress intensity factors for mode-II and mode-III [12-17].

The influence of crack length on the growth path as one of principal reasons which leads to failure issue where it is predicted the behaviour of crack by calculate the stress intensity factor [14-17]. The investigation of failure behaviour of patch ordinary or composite is important where the effect of patch factors such as patch material and its dimensions on the repair is analyzed using three-dimensional finite element method [14-19].

Recently there are some studies for circumferential crack of elbow under internal pressure where they present some solutions about stress intensity factors for mode by the finite element method [20,6]. The study by numerical simulation especially the finite element method is a very important procedure to find the prevention solution of pipeline crack problems. In order to obtain accurate of simulations results, real boundary conditions of piping systems must be used [22, 20]. The problem of thin elbow is situated in sensitive zones especially extrados and crown of elbow, where it has very influence on the increasing behaviour of elbows [23]. It is very important to study the circumferential welding on pipe 
bends which allow studying the effect of elbow form changes on the stress distribution and cracks behaviour of pipelines according to the operating conditions [23, 22]. To study the crack of pipeline the finite element method is being applied to calculate stress intensity factor along the crack of pipeline for two cases straight line or elbow [23, 2-6]. The aim of this work is to obtain the suitable solutions of a cracked elbow by composite patch for transport safely the oil and gas by complex piping systems. The reliable safety for the transfer of energy depends on several principal points such as good design, pipelines materials and operating conditions despite all the precautions necessary for the construction and installation of pipelines, but show some defects in the sensitive areas of the pipeline and especially the areas of the elbow and welding. To repair and analyse these problems, three dimensional-finite element methods are applied to present the results of stress intensity factor which give the accurate information about the small cracks. In this study, we are based on two parts: firstly, we calculate the stress intensity factor around the elbow cracks, and secondly, we propose the solution by patch taking into account the geometry, adhesive nature and patch.

\section{GEOMETRY}

This study is based, firstly to evaluate the propagation of crack along the elbow of pipeline for different angles and to show the efficiency of the composite patch. The geometry used in this study is shown in figures 1 and 2, where the outer diameter and the wall thickness are $362.8 \mathrm{~mm}$ and $20.9 \mathrm{~mm}$ respectively [21-24]. Three-dimensional finite element method is used for repairing circumferential cracks in pipeline elbow with composite materials (glass/epoxy, carbon/epoxy and graphite/epoxy), where the elbow is influenced by fluid pressure transfused. The size of the elbow bend radius is $\mathrm{R}=700 \mathrm{~mm}$, and the circumferential crack is represented by the angle $\theta$.

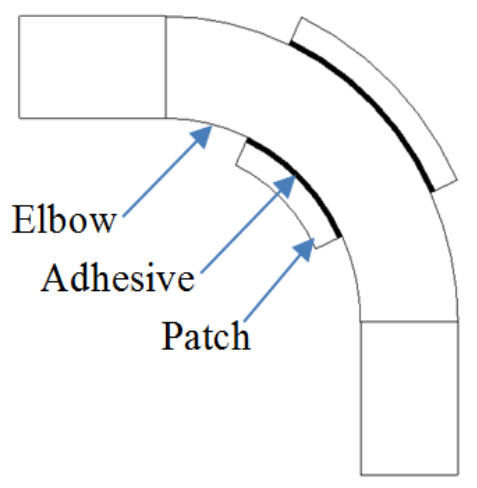

Figure 1 . Geometry of a $90^{\circ}$ elbow with patch.

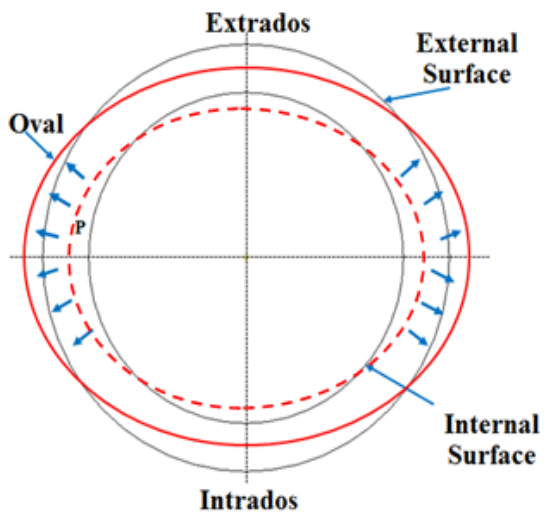

Figure 2. Different zones of elbow cross section after deformation (oval form). 


\section{MATERIAL}

In this study the material SA312 stainless steel is used for improving the quality of the pipeline. In order to effectively repair the cracked elbow, the patching technique is based on the composite patch and layer adhesive FM73. Table 1 presents the mechanical properties of the pipeline, the patch and the adhesive.

Table 1. Material properties

\begin{tabular}{|c|c|c|c|c|c|c|c|c|c|}
\hline & $\begin{array}{c}\mathrm{E}_{1} \\
(\mathrm{GPa})\end{array}$ & $\begin{array}{c}\mathbf{E}_{2} \\
(\mathbf{G P a})\end{array}$ & $\begin{array}{c}\mathbf{E}_{3} \\
(\mathbf{G P a})\end{array}$ & $v_{12}$ & $v_{13}$ & $\mathbf{v}_{23}$ & $\begin{array}{c}\mathbf{G}_{12} \\
(\mathbf{G P a})\end{array}$ & $\begin{array}{c}\mathbf{G}_{23} \\
(\mathbf{G P a})\end{array}$ & $\begin{array}{c}\text { G13 } \\
(\text { GPa) }\end{array}$ \\
\hline $\begin{array}{l}\text { Patch Glass / } \\
\text { Epoxy }\end{array}$ & 150 & 25 & 25 & 0.21 & 0.21 & 0.21 & 7.2 & 5.5 & 5.5 \\
\hline $\begin{array}{l}\text { Patch } \\
\text { Graphite / } \\
\text { Epoxy }\end{array}$ & $\begin{array}{c}132.5- \\
173.3\end{array}$ & $\begin{array}{c}10.7-- \\
10.8\end{array}$ & $\begin{array}{l}10.7- \\
10.8\end{array}$ & $\begin{array}{l}0.24- \\
0.46\end{array}$ & $\begin{array}{l}0.24- \\
0.46\end{array}$ & $\begin{array}{c}0.26- \\
0.49\end{array}$ & $\begin{array}{l}5.4- \\
5.7\end{array}$ & $\begin{array}{l}3.4- \\
3.7\end{array}$ & $\begin{array}{l}5.4- \\
5.7\end{array}$ \\
\hline Patch & & & & & & & & & \\
\hline $\begin{array}{l}\text { Carbon / } \\
\text { Epoxy }\end{array}$ & 131.6 & 8.2 & 8.2 & 0.25 & 0.017 & 0.3 & 4.5 & 4.5 & 4.5 \\
\hline $\begin{array}{l}\text { Adhesive } \\
\text { FM73 }\end{array}$ & 2.55 & & & 0.32 & & & & & \\
\hline Elbow SA312 & 207 & & & 0.3 & & & & & \\
\hline
\end{tabular}

\section{FINITE ELEMENT MODELING}

All cracks problems of piping systems will be repaired by improving the quality of composite patch and adhesive. In order to study the effects for different mechanical and geometrical properties of the repair components with adhesive are very important where we use the SIF to analyze the pipeline repair in the elbow cracked case [25]. The finite element simulations are performed using Abaqus. The finite element method is used to investigate of cracked elbow of various crack angles under internal pressure and with the bending angle $90^{\circ}$ as showed in Figure 3 [25,5].

The FE mesh for the crack is shown in Figure 3. The elbow crack was meshed at critical zone using three-dimensional hex-dominated quadratic elements. For improving the SIF data, the elbow is able to be used where the simulation on crack zone is carried out using the 20-node brick elements with mesh refinement near the crack tip [20-25].

For precision, mainly the mesh in the crack front was refined in the elbow crack to simulate the stress intensity factor [25-30].

$$
K=\sigma \sqrt{\pi r \theta} \cdot F
$$

Where $\mathrm{r}$ is radius, $\theta$ is crack angle, $\mathrm{F}$ is the force and $\sigma$ is the nominal stress. 
The material property values of Young's modulus and Poisson's ratio were taken to be $E=204 \mathrm{GPa}$ and $v=0.3$, respectively. To study pipeline crack, it can be noted that the accurate approach is a very important step to predict the behavior of cracked elbow as shown in figure 3 [27].

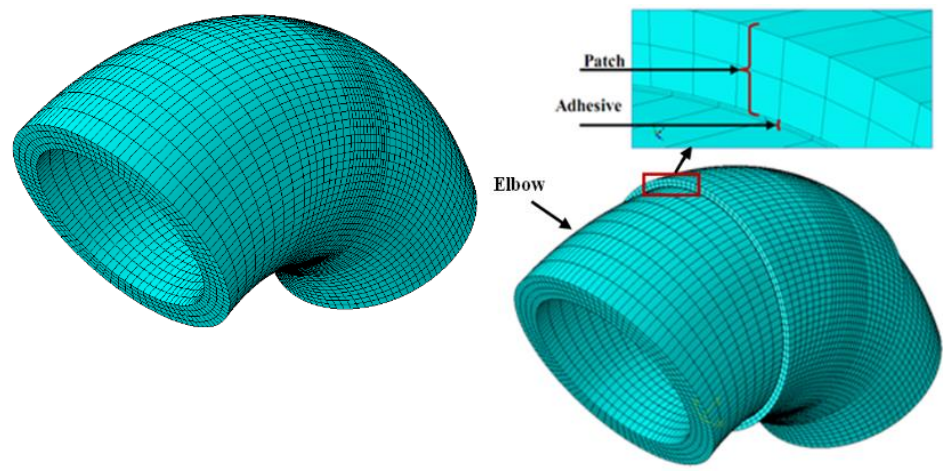

Figure 3. The typical finite elements mesh of an elbow with and without patch

\section{RESULTS AND DISCUSSION}

The objective of this work is to predict the behavior of repaired crack for the SA312 Type 304 stainless steel pipeline by using three dimensional (FEM). The composite patch under analysis is Glass / Epoxy patch and adhesive FM73 under the internal pressure in order to evaluate the stress intensity factor (SIF). Piping systems bends at $90^{\circ}$ are the weak zone in transport of hydrocarbons and can lead to fatigue damage. The mechanical and the geometrical characteristics of composite patch and adhesive play an essential role to repair the pipeline elbow under internal pressure, crack angle and bend angle [25-29]. Basically, the numerical three-dimensional method shows several results for cracked elbow and it's repaired by composite patch to increase lifetime of piping system [25-29].

\section{SIF versus the crack angle with deferent pressure}

The variation of SIF with angle crack for different pressures is investigated. It has been observed that the values of SIF increases with the increase of crack angle [26, 27, 5]. It is seen that the distribution of the stress especially in the zone of great stresses is related with the dangerous cracks zones [27-29]. The results of SIF for crack elbow of piping systems are investigated along of the crack front for different pressures. The figures 4 and 5 present the variation of the SIF versus the crack angle with the presence of three values of pressures 50, 60 and 70 bar.

It is noticed that the SIF increases proportionally with the increasing crack angle as shown in figure 5. The effect of pressure along the elbow of pipeline is essential where the moving energy the cracked piping systems allow the increase of the SIF. The numerical results are shown that the reinforcing by composite patch with adhesive was considered to be suitable solution for the cracked elbow. 


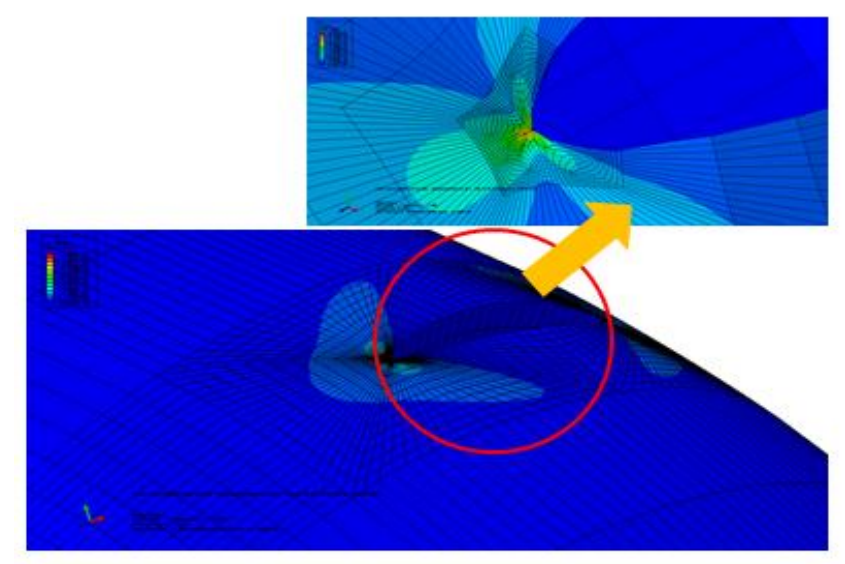

Figure 4. Crack angle in the elbow

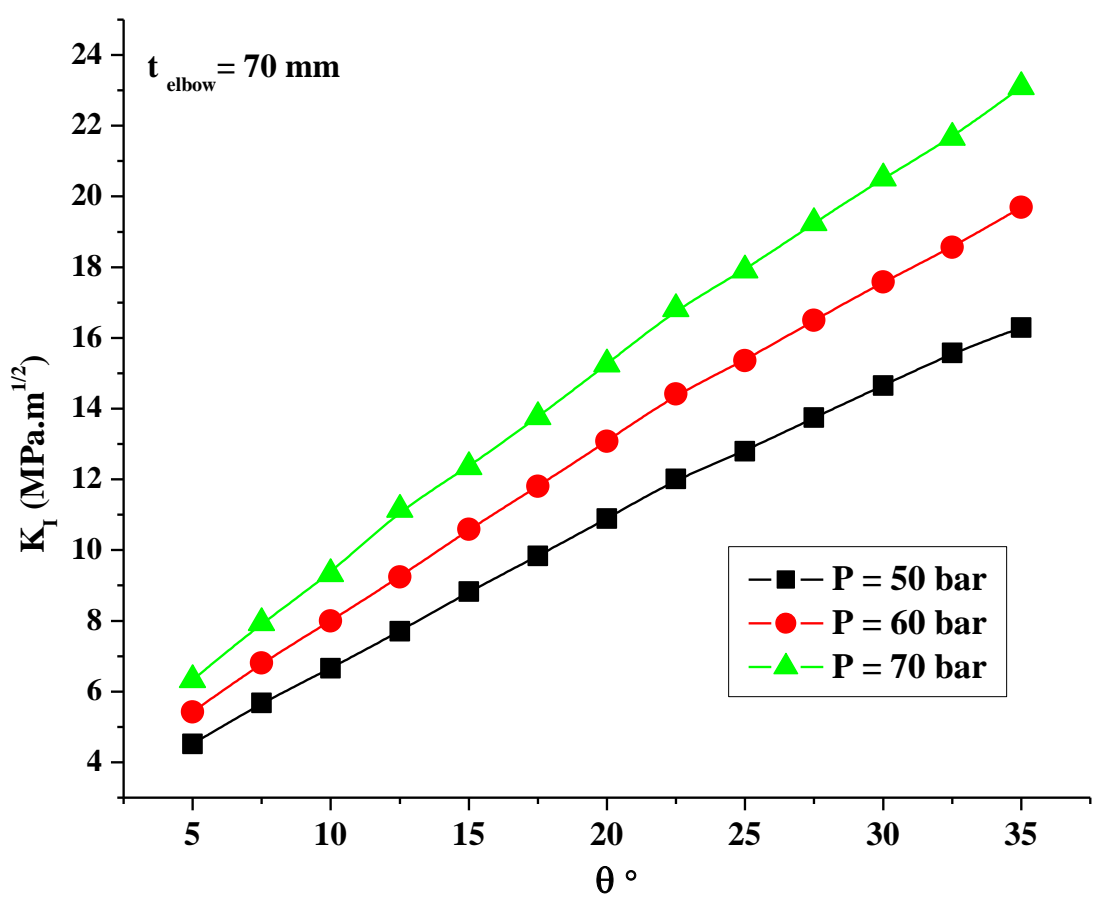

Figure 5. SIF against crack angle for deferent pressure.

Focus on the pipeline bend damage is important in the study of the shape of crack. However, the influence of internal pressure can be depended to define the behavior of the propagation of small cracks. The behavior of circumferential crack at extrados or intrados in elbow under internal pressure is very important to predict the hydrocarbons transport problems.

\section{Thickness effect in the elbow}

The obtained results show the influence of elbow thickness with/without patch on stress intensity factors which depend as the thickness of pipeline for cracked elbow taking into 
account the different pressures and angle of the cracked elbow [28-29, 26]. Several states have been studied by varying the elbow thicknesses for different pressures 50,60 and 70 bar respectively, at $15^{\circ}$ of crack angle without patch as shown in the figures 6 . These results show two zones for different pressures and cracks angles. In the first zone, the stress intensity factors decrease rapidly towards the elbow thickness, nearly $10 \mathrm{~mm}$. In the second zone of the curves greater than $55 \mathrm{~mm}$, the stress intensity factors decrease linearly for different pressures. In this situation, it can be noted that the decrease of elbow thickness allows to increase of the stress intensity factors (SIF) which indicated to increase the rate of the crack growth [30-32]. To show the important role of the patch especially the composite patch in the cracked elbow, a several analysis has been performed by varying the pressures 50,60 and 70 bar respectively as shown in the figure 7 . This change in the behaviour as result of the increasing thickness of elbow patched wall where the composite patch resists most of the stresses of pressure.

The objective of this study is to analysis the resist of the stresses in the extrados zone of elbow where the increasing of thickness of elbow is one of the key factors which influence the efficiency of elbow for example at 50 bar (figure 7) [33, 29]. The numerical results indicated that the SIF values for the thickness of elbow at $15^{\circ}$ of crack angle, decreased speedily and then took a stable value in the cracked elbow. It can be noted that the composite patch played important role to repair the zones of fracture $[31,28]$. In the results, we noticed that the increase of elbow thickness leads to decrease the crack rate, which means that a great elbow thickness is recommended to avoid the crack phenomenon especially in the elbow [33].

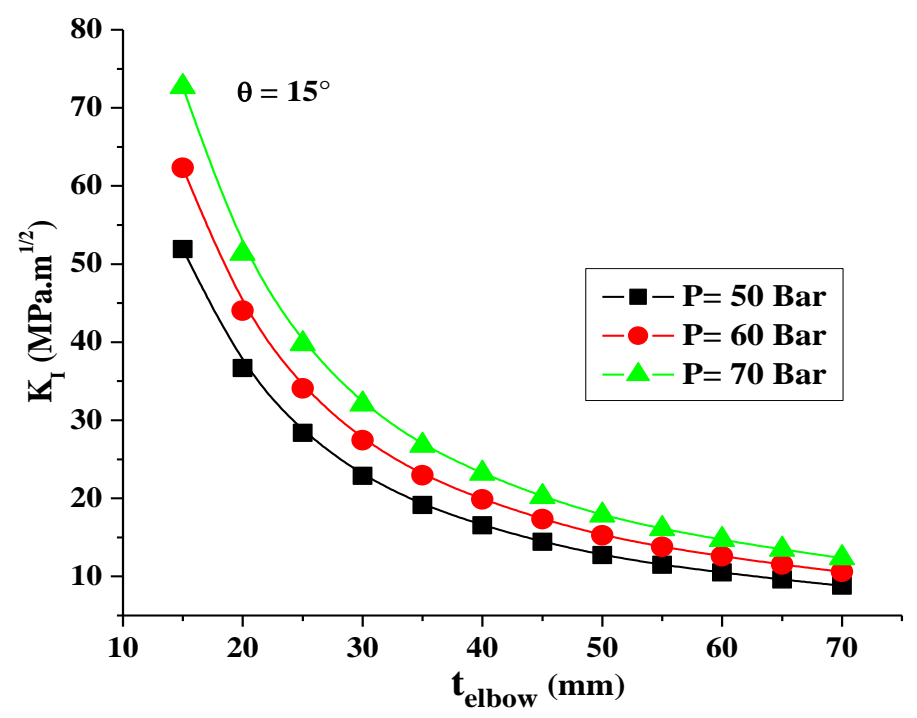

Figure 6. SIF against thickness of elbow without patch for deferent pressures. 


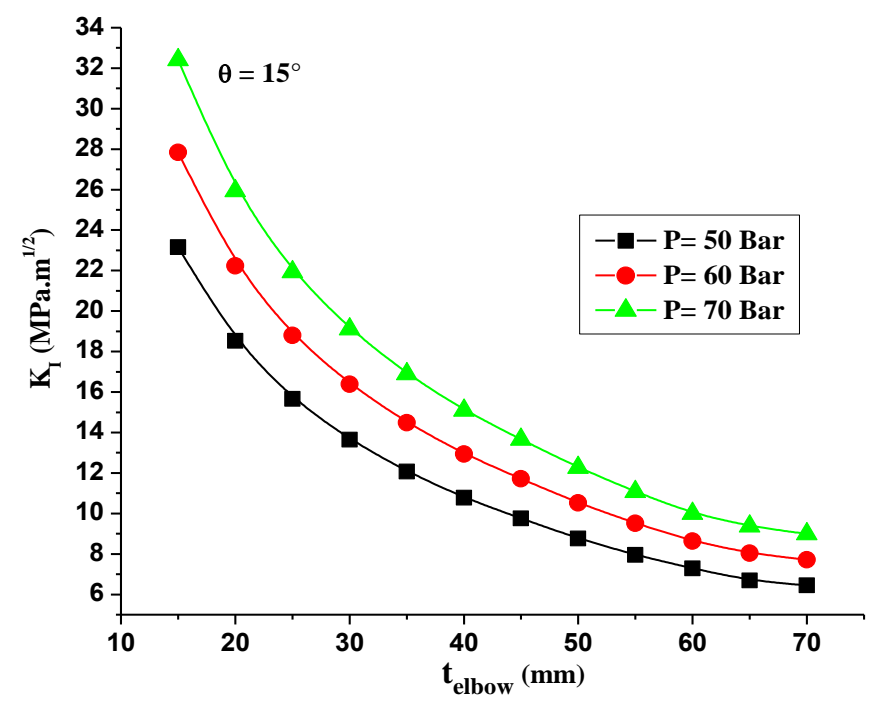

Figure 7. SIF against thickness of elbow with patch for deferent pressures.

\section{Effect of the elbow radius}

Figures 8 and 9 show the SIF versus the elbow radius of cracked elbow tip for internal and external zones where the SIF results confirmed that the external position of cracks is more affected than the internal position especially when the values of elbow radius greater than 600 $\mathrm{mm}$ [34-36]. The percentage nearly of 50\% is the reduction ratio of SIF in elbow between two positions, this shows that a high elbows radius at external position allows to transfer the stresses to the critical zone through small period and thus it lead to increase the SIF [34-35]. After an analysis of results, we can conclude that the repairing by the composite patch is necessary for thin walled elbow [34-36].

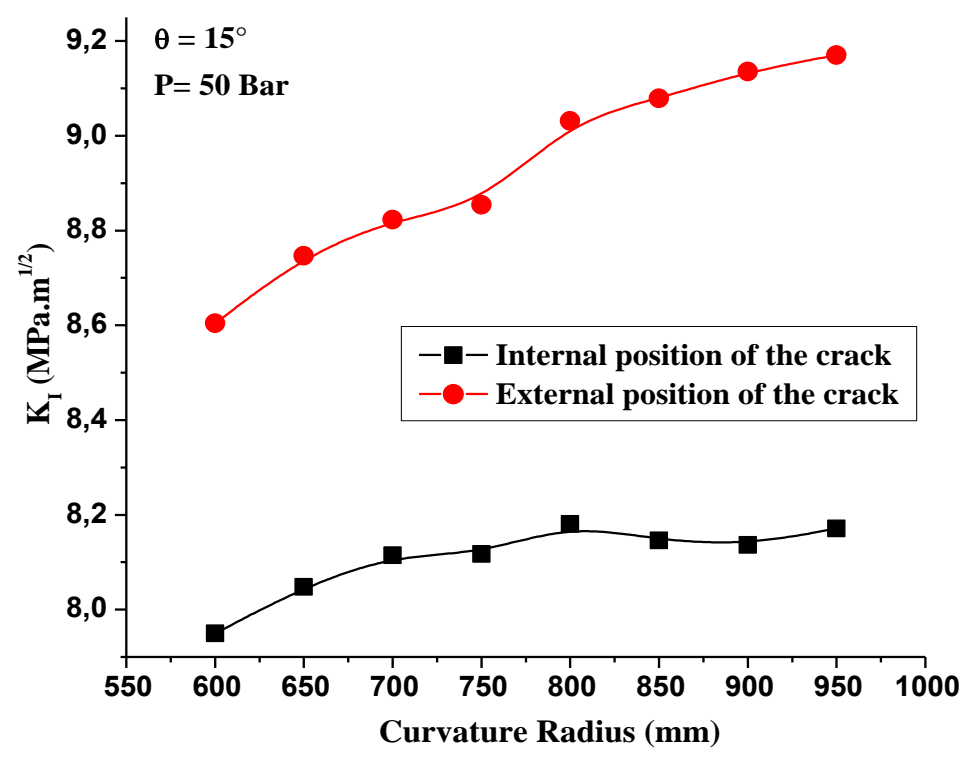

Figure 8. SIF against curvature radius for elbow. 


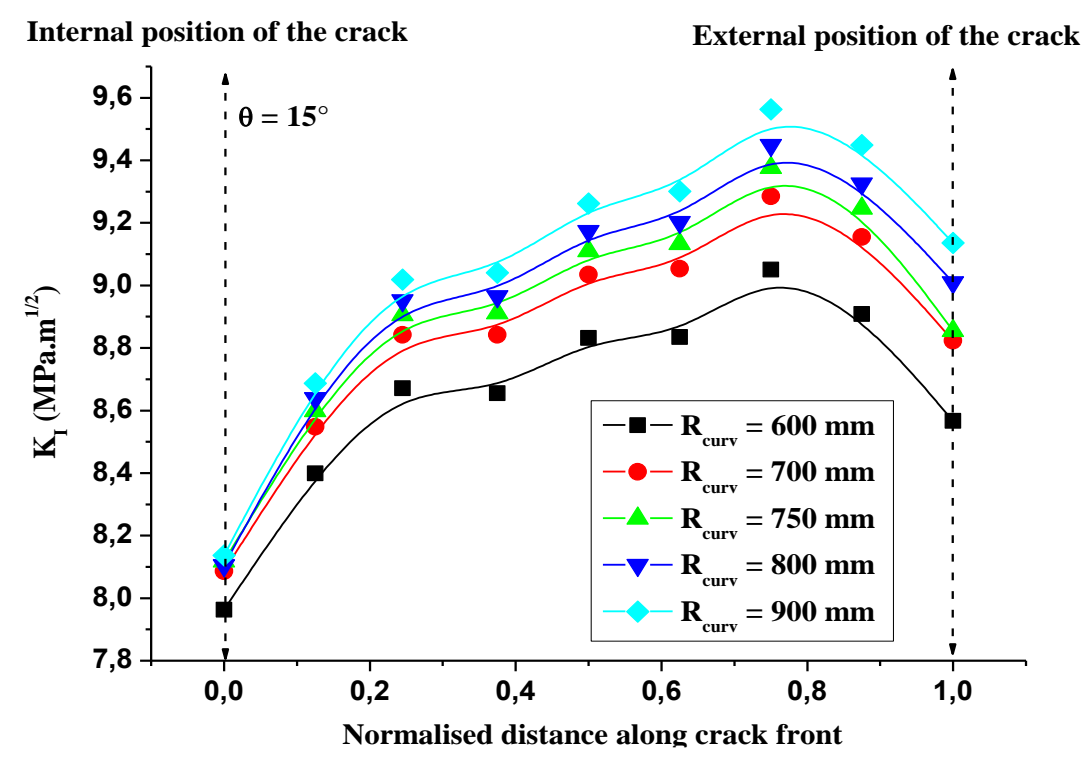

Figure 9. SIF against normalized distance along crack front for different elbow radius.

\section{Effect of the patch thickness on the elbow cracked}

In this study, the effect of the composite patch thickness shows on the repair of cracked elbow which depends on the impact of crack angles and pressures as shown in the figures 10 and 11. It is seen that the crack propagation from the cracked elbow to the composite patch through the adhesive layer length has an important influence on the SIF values taking into account the adhesive quality, where by the proportional method; we can observe that the increase of the patch thickness and the decreases the SIF at the cracked piping system enables to avoid the failure phenomenon [34-35, 26].

To improve the repaired, we must select the new mechanical parameters of the composite patch and adhesive [34-36]. The results confirmed that the accuracy of choosing the thickness of the patch lead to improve the repair of the pipeline. The increase of patch thickness leads to decrease the SIF from 7 MPa.m ${ }^{1 / 2}$ to $6.15 \mathrm{MPa}^{1 / 2}$. In addition, the stress uniform distribution helpful for composite patch in the critical zones taking into account the adhesive nature. 


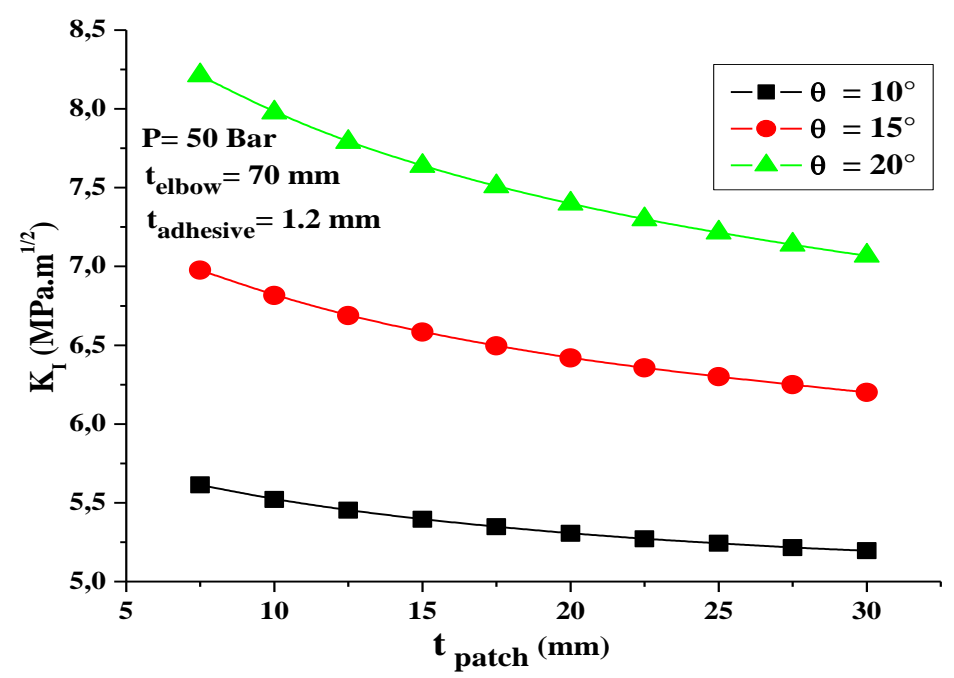

Figure 10. SIF vs. thickness of patch

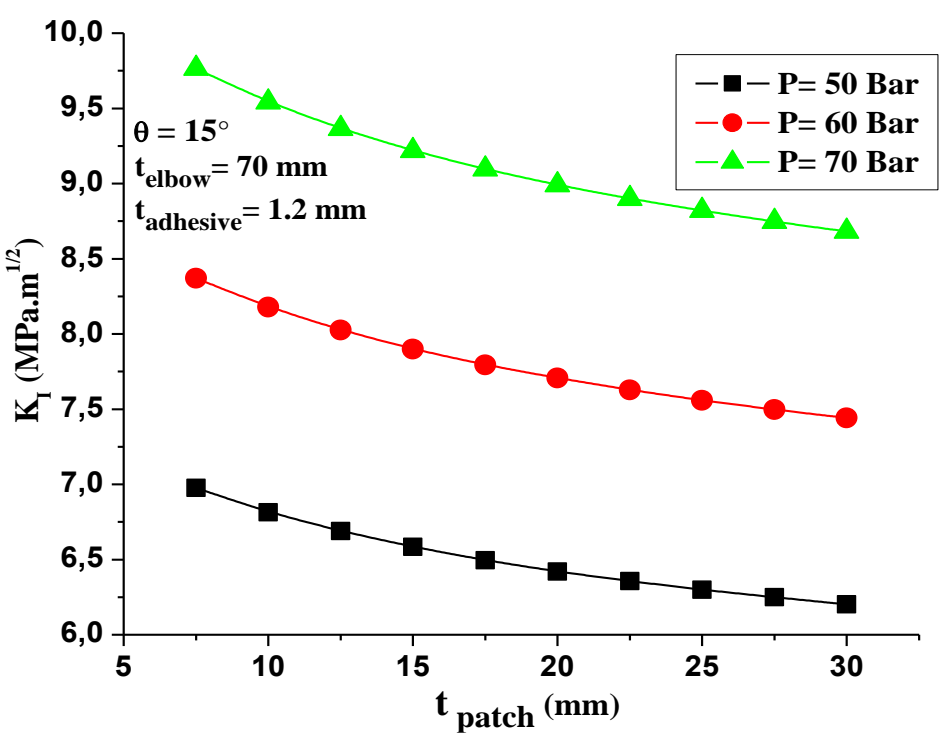

Figure 11. SIF vs. deferent values of thickness for patch.

\section{Adhesive role in the elbow repair}

The adhesive layer is one of an important part in the repair technique of cracked elbow where it is depended on the geometry and material nature. The principal role of the adhesive is transfer of the energy (stress) of crack to the composite materials (patch). 


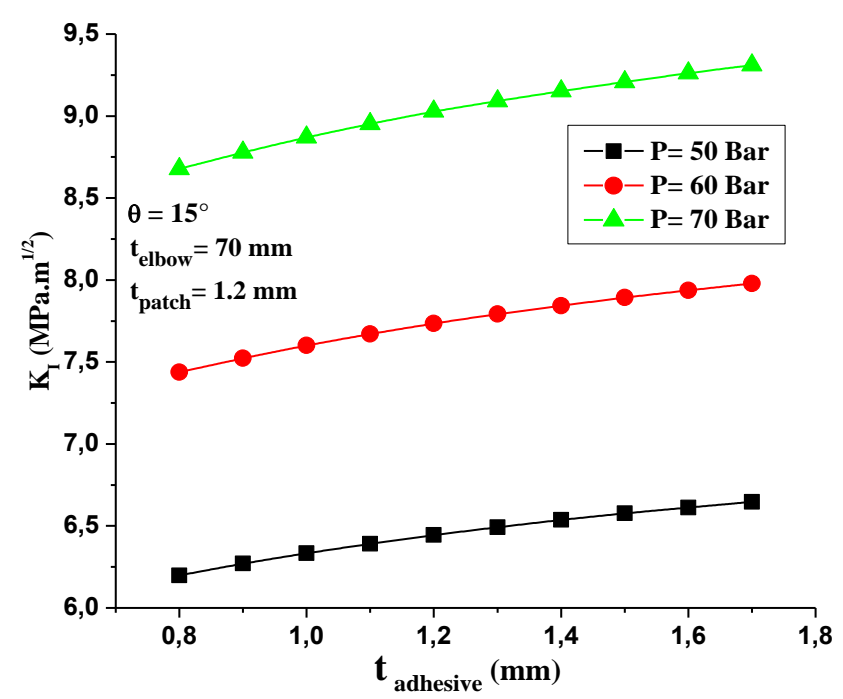

Figure12. SIF against adhesive thickness for deferent pressure.

The adhesive layer is one of an important part in the repair technique of cracked elbow where it is depended on the geometry and material nature. The principal role of the adhesive is transfer of the energy (stress) of crack to the composite materials (patch). The repair by composite patch at crack angle $15^{\circ}$ along elbow in the circumferential cracked is investigated by the stress intensity factors (SIF) which are shown in the figure 12. The composite patch with adhesive is played a significant role on the repair technique of cracked elbow, where the SIF is decreased in the cracks external position due to the direct contact between the cracks and the composite patch which absorbed the stress [34-36]. For example, the figure 12. is shown the results of the repair by FM73 adhesive type where the SIF values increased to 7.8 $\mathrm{MPa} \cdot \mathrm{m}^{1 / 2}$ at the maximal pressure during $0.9 \mathrm{~mm}$ of adhesive thickness. The pressures at zones weld of pipeline led to problems crack, where the effect of the pressure along the elbow of pipeline is important where the energy moves from the cracked piping systems and allows the increase of the SIF [34-36].

\section{Effect of the patch nature in the repaired}

The analysis of the stress intensity factor values between the external and internal crack positions shows a major problem in repairing pipeline. Thus, the prediction of crack propagation becomes very important to avoid many problems such as the failure and corrosion issue. The simulated results of SIF at cracked elbow between an internal and an external positions allow to analyze the behavior along the crack in order to study the crack structure internal. This phenomenon allows to enhance the role and the feature of composite patch that govern the crack propagation at $15^{\circ}$ crack angle [34, 12-19].

Repairing by composites patch (carbon/epoxy, glass/epoxy and graphite/epoxy) allow the distribution regularly of stresses transfer in the crack of the wall elbow of the repaired zone [34-36]. The figures 13 and 14. show to explain the impact of patch in the repair operation especially using the composite materials where the stress intensity factor (SIF) versus patch thickness at the crack tip is very important for using the composites patch. The results show that the increased thickness of the patch led to decrease the SIF for extern surface where the patch technique allows improving the efficiency of the pipeline. The decrease of SIF is the 
conclusive proof for good absorption of the crack energy by patch and adhesive [34-36]. The figure 14. show that the repairing by the carbon/epoxy patch is the best material composite than the glass/epoxy and graphite/epoxy to absorb the largest stress for cracking of elbow. It is seen that in external crack is shown the decreasing of the stress from $8.5 \mathrm{MPa} . \mathrm{m}^{1 / 2}$ to $5.5 \mathrm{MPa} . \mathrm{m}^{1 / 2}$ with the reduction about 35\% [34-36]. It should be noted that the repair of external cracks in pipeline is more efficient than the internal cracks. According to the precedent results, we can conclude that the performances of the pipeline repair are convenient for thin walled pipelines [34-36].

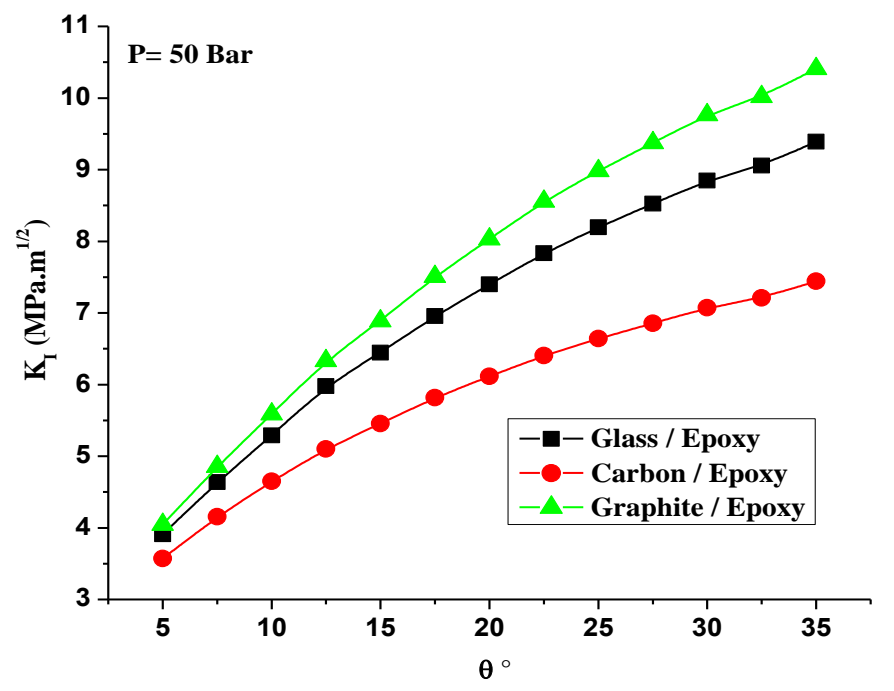

Figure 13. Distribution of SIF along the crack front for different composite patch.

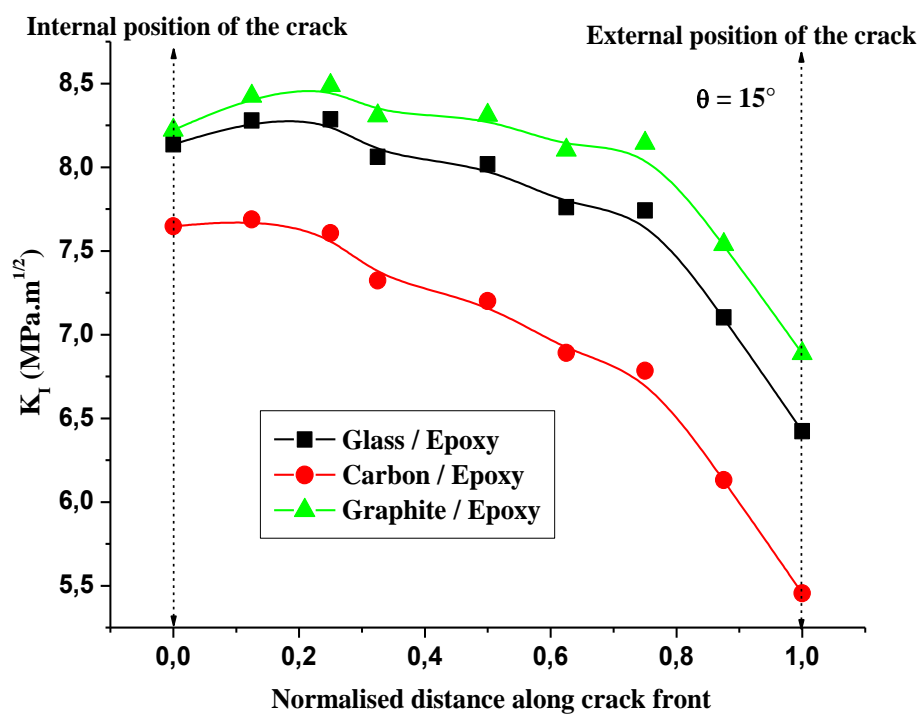

Figure 14. SIF vs. normalized distance along crack front with different patch nature

The repairing by the composite patch is become one of the best solutions to reduce the crack growth $[34,36]$ where the adhesive layer plays the principal role where it allows to transfer the crack energy from the external surface of the elbow to the composite patch. Decreasing 
the SIFs indicate that the energy crack is absorbed by the adhesive layer taking into account the thickness of adhesive [34,36]. In effect, the dispersion of crack energy along the thickness of adhesive layer and composite patch is solution of this complex phenomenon. Thus, these results allow to predict the behavior of elbow crack take into consideration the operating conditions.

\section{CONCLUSION}

In this study, different composite patches such as carbon/epoxy, glass/epoxy and graphite/epoxy were used to repair the cracked elbow at $15^{\circ}$ of crack angle. This analysis focused to compute of stress intensity factors using the finite element method along the crack, in order to predict the behavior of crack growth and to effect the patching system in the critical zones of cracked elbow. The decrease of the stress intensity factor by the composite patch is the major objective in this study where it is very important at external zone of cracks which allow prolonging the repairs life [34-36]. Thus, the most studies continuing have focused on improving the efficacy the nature and geometry of composite materials, and the possibility of the re-use of pipeline. The results showed the variation of the stress intensity factor (SIF)in the presence of different conditions such as pressures, cracks angles and, geometry of the patch and adhesive which are all important to repair the pipeline. It can be concluded that the importance of repair is influenced by a lot of factors such as the nature of adhesive and patch, and zones cracked taking into account the operating conditions. As a result, it can be noted that the prediction of crack behavior is analyzed by the stress intensity factors values which were decreased by the importance of patch repair. Hence, it can be noted that the repairing the crack by patch leads to decreasing the costs and increasing the lifetime.

\section{REFERENCES}

[1] Srivastava A, Prabhakaran KM, Ghosh AK. Studies on the behavior of part-through circumferential crack at intrados in elbows under in-plane bending moment. Nuclear Engineering and Design. 2011; 241: 2386-2397.

[2] Natarajan R, Mirza S. Effect of thickness variation on stress analysis of piping elbows under internal pressure. Comp. Structures. 1984; 18:767-778.

[3] Thomas K. The effects of geometric irregularities on the design analysis of thinwalled piping elbows. J. Pressure Vessels Technology. 1980;102: 410-418.

[4] Zhang S, Gao CR, Zhao DW, Wang GD. Limit Analysis of Defect-Free Pipe Elbow Under Internal Pressure With Mean Yield Criterion. International Journal of Iron and steel research. 2013; 20:11-15.

[5] Chattopadhyay J. The effect of internal pressure on in-plane collapse moment of elbows. Nuclear Engineering and Design. 2002;212:133-144.

[6] Joong-Hyok A, Yun-Jae K, Peter JB. Elastic stress intensity factors and crack opening displacements for circumferential through-walled cracked elbows. Engineering Fracture Mechanics. 2010;77:2821-2839.

[7] Shunhu Z, Xiaonan W, Binna S, Dewen Z. Limit analysis based on GM criterion for defect-free pipe elbow under internal pressure. International Journal of Mechanical Sciences. 2014;78:91-96. 
[8] Bin Q, Yadong L, Changrong Y, Xin W. Through-thickness welding residual stress and its effect on stress intensity factors for semi-elliptical surface cracks in a buttwelded steel plate. Engineering Fracture Mechanics. 2018;193:17-31.

[9] Yuan H, Liu WJ, Xie YJ. Mode-I stress intensity factors for cracked special-shaped shells under bending. Engineering Fracture Mechanics. 2019;207:131-148.

[10] Volkan A, Ramazan K, Tuba A. Improvement of load carrying capacity of sandwich composites by different patch repair types. Polymer Testing. 2018;72 :257-262.

[11] Xiaojing C, Ri X. Mingchen H, Jinquan X. A threshold formula for fatigue crack growth with mean stress intensity factors. International Journal of Mechanical Sciences. 2018;135:639-645.

[12] Dursahib. SB, Jefferson AJ, Balaganesan G, Arockiarajan A. The role of patch-parent configurations on the tensile response of patch repaired carbon/epoxy laminates. Polymer Testing. 2018;70:413-425.

[13] Huang T, Yang JJ, Jin J, Wen PH, Aliabadi MH. Evaluation of stress intensity factors and T-stress by finite block method: Static and dynamic. Theoretical and Applied Fracture Mechanics. 2018;93:222-232.

[14] Huan Li, Ran G, Heming C. Calculation of stress intensity factors of matrix crack tip in particle reinforced composites using the singular Voronoi cell finite element method. Theoretical and Applied Fracture Mechanics. 2019;101:269-278.

[15] Minmao L, Pan Z. An improved approach for computation of stress intensity factors using the finite element method. Theoretical and Applied Fracture Mechanics. 2019;101:185-190.

[16] Botong Z, Mina D. Fatigue crack growth analysis of steel elements reinforced with shape memory alloy (SMA)/fiber reinforced polymer (FRP) composite patches. Composite Structures. 2017;164:158-169.

[17] Emre K, Ali OA. Three-dimensional mixed-mode stress intensity factors for deflected internal surface cracks in thin and midsize-thick-walled spherical pressure vessels. International Journal of Pressure Vessels and Piping. 2019;171:10-33.

[18] Amir N. Numerical investigation on stress intensity factor in railway wheelset under the influence of residual stresses induced by press fitting process. Engineering Failure Analysis. 2018;94:78-86.

[19] Yuliang H, Ying T, Cheng L. Thaneshan Sapanathan, Mohamed Rachik, Lowvelocity impact behaviors of repaired CFRP laminates: Effect of impact location and external patch configurations. Composites Part B. 2019;163:669-680.

[20] Jaehyung K, Klaus-Jürgen B. The finite element method enriched by interpolation covers. Computers and Structures. 2013;116:35-49.

[21] Fonseca EMM, De Melo FJMQ, Oliveira CAM. Numerical analysis of piping elbows for in-plane bending and internal pressure. Thin-Walled Structures. 2006;44:393-398.

[22] Hyde TH, Becker AA, Sun W, Williams JA. Influence of geometry change on creep failure life of 908 pressurized pipe bends with no initial ovality. International Journal of Pressure Vessels and Piping. 2005;82:509-516.

[23] Hongrui S, Gang C, Yong W, Xu C. Ratcheting behavior of pressurized elbow pipe with local wall Thinning. International Journal of Pressure Vessels and Piping. 2013;102(103):14-23.

[24] Zhang YM, Yi DK, Xiao Z, Huang ZH, Kumar SB. Elasticeplastic fracture analyses for pipeline girth welds with 3D semi-elliptical surface cracks subjected to large 
plastic bending. International Journal of Pressure Vessels and Piping. 2013;105 (106):90-102.

[25] Bezzerrouki M, Albedah A, Bachir BB. Ouddad W, Benyahia F. Computation of the stress intensity factor for repaired cracks with bonded composite wrap in pipes under traction effect. Composite Materials Journal of Thermoplastic, SAGE. 2012; 26(6): 831-844.

[26] Khan MA. Meraha N, Muhammad JA. 3D effects on crack front core regions, stress intensity factors and crack initiation angles Shafique. International Journal of Solids and Structures. 2013;50:1449-1459.

[27] Shlyannikov VN, Zakharov AP. Multiaxial crack growth rate under variable T-stress. Engineering Fracture Mechanics. 2014;123: 86-99.

[28] Ouinas D, Bachir BB, Achour B, Benderdouche N. Modelling of a cracked aluminium plate repaired with composite octagonal patch in mode I and mixed mode. Materials and Design. 2009;30:590-595.

[29] Miyazaki N, Shibata K. Stress Intensity Factor Analyses of Surface Cracks in Threedimensional Structures-Comparison of the Finite Element Solutions with the Results Obtained by the Simplified' Estimation Methods. Int. J. Pres. Ves. \& Piping. 1984;15:37-59.

[30] Linxia G, Ananth RMK, Shijia Z. Finite element analysis of cracks in aging aircraft structures with bonded composite-patch repairs. Composites: Part B. 2011;42:505510.

[31] Bachir BB, Ouinas D., Serier B, Benderdouche N. Disbond effects on bonded boron/epoxy composite repair to aluminium plates. Computational Materials Science. 2008;42:220-227.

[32] Meriem-Benziane M, Abdul-Wahab S, Zahloul H, Babaziane B, Mohamed H, Pluvinage G. Finite element analysis of the integrity of an API X65 pipeline with a longitudinal crack repaired with single- and double- bonded composites. Composites Part B: Engineering. 2015;77: 431-439.

[33] Chao-Shi C, Chia-Hau C, Ernian P. Three-dimensional stress intensity factors of a central square crack in a transversely isotropic cuboid with arbitrary material orientations. Engineering Analysis with Boundary Elements. 2009;33:128- 136.

[34] Rodriguez D, Ochoa OO. Flexural response of spoolable composite tubulars: an integrated experimental and computational assessment. J Compos Sci Technol. 2004;64(13-14):2075-88.

[35] Kim W, Ochoa OO, Miller C. Axial and burst analysis of offshore omposite risers. In: Proceedings of 20th annual technical conference of the American society for composites. (Philadelphia, PA), September; 2005.

[36] Bezzerrouki M, Bachir BB, Ouinas D. SIF for cracks repaired with single composite patch having two adhesive bands and double symmetric one in aircraft structures. Computational Materials Science. 2008;44:542-546. 